\title{
AVALIAÇÃO DO DESEMPENHO DO REATOR ANAERÓBIO DE MANTA DE LODO (UASB) EM ESCALA LABORATORIAL NA REMOÇÃO DA CARGA ORGÂNICA DE ÁGUAS RESIDUÁRIAS DA SUINOCULTURA
}

\author{
Performance evaluation of a lab-scale upflow anaerobic sludge blanket reactor (UASB) \\ removing organic loading rate from swine manure
}

\author{
Cláudio Milton Montenegro Campos ${ }^{1}$, Leonardo Henrique Soares Damasceno ${ }^{2}$, \\ Emerson Teruaki Mochizuki ${ }^{3}$, Cláudio Gouvêa Botelho ${ }^{4}$
}

\section{RESUMO}

Objetivou-se com o presente trabalho avaliar o desempenho do reator anaeróbio de manta de lodo (UASB-Upflow Anaerobic Sludge Blanket) construído em escala laboratorial na redução da carga orgânica poluidora dos despejos suinícolas brutos. O sistema completo foi composto de um tanque de acidificação e equalização, reator UASB e lagoa aerada facultativa. O tempo de detenção hidráulica (TDH) e temperatura adotada para o reator UASB foram de 30 horas e $30{ }^{\circ} \mathrm{C}$, respectivamente. Os valores médios afluentes de $\mathrm{DQO}_{\mathrm{T}}$, ST e SVT foram de 1806, 1810 e $1240 \mathrm{mg} . \mathrm{L}^{-1}$. As eficiências de remoção de DQO SVT foram de 84, 58 e 73\%, respectivamente. O sistema se apresentou-se estável, com boas condições de tamponamento, retenção e digestibilidade de sólidos, demonstrando que os critérios adotados foram adequados, principalmente aqueles referentes ao TDH, carga orgânica volumétrica (COV) e temperatura.

TERMOS PARA INDEXAÇÃO: Água residuária da suinocultura, reator UASB, tratamento anaeróbio.

\begin{abstract}
The present work was carried out in order to evaluate the performance of a lab scale Upflow Anaerobic Sludge Blanket reactor (UASB) treating liquid effluent from swine manure without solids separation. The treatment system consisted of one acidification tank, which also equalized the substrate, an UASB reactor, and an aerated facultative pound. The hydraulic retention time (HRT) and temperature adopted for the UASB reactor were $30 \mathrm{~h}$ and $30^{\circ} \mathrm{C}$, respectively. The influent average values of Chemical Oxygen Demand (COD), Total Solids (TS) and Total Volatile Solids (TVS) were 1806, 1810 and 1240 mg. $\mathrm{L}^{-1}$. The removal efficiencies were 84,58 and $73 \%$, respectively. The system presented good stability and buffering conditions, and also a good solids digestibility, showing that the research criteria adopted was adequate, mainly those parameters referred to the HRT, Volumetric Organic Loading Rate (VOLR) and temperature.
\end{abstract}

INDEX TERMS: Swine manure, UASB reactor, anaerobic treatment.

(Recebido para publicação em 16 de dezembro de 2002 e aprovado em 19 de Janeiro de 2005)

\section{INTRODUÇÃO}

As atividades agroindustriais têm se voltado não somente para a produção e a produtividade, mas também para a conservação do meio ambiente. Essa mudança no comportamento do empresário agrícola está ligada não somente à conscientização da importância do problema, mas principalmente a uma exigência do mercado, seja para a exportação ou para consumo interno. Os consumidores, cada vez mais, dão preferência a produtos que possuem parâmetros de qualidade, de acordo com normas internacionais e nacionais (ISO 9000, ISO 14000, "Selo Verde”, etc.).
Em termos econômicos e sociais, a suinocultura possui um papel importante, principalmente como instrumento de fixação do homem no campo, mas, em contrapartida, os resíduos gerados durante o processo de produção possuem grande potencial poluidor, sendo considerado pelos órgãos de gerência ambiental como uma das atividades mais degradadoras do meio ambiente (CAMPOS et al., 1999). Quando manejados em fossa de retenção em unidades de terminação, os dejetos de suínos chegam a apresentar valores de Demanda Bioquímica de Oxigênio (DBO) de 50.000 mg.L ${ }^{-1}$ (OLIVEIRA, 1993).

O rebanho mundial de suínos, em 2000, segundo

\footnotetext{
1. Professor Adjunto IV, PhD. - Departamento de Engenharia da Universidade Federal de Lavras/UFLA - Caixa Postal 3037 - $37.200-000$ Lavras,MG - cmmcampos@ufla.br

2. Engenheiro Agrícola M.Sc. - Departamento de Engenharia/DEG - Universidade Federal de Lavras/UFLA - Ihsd@dr.com

3. Engenheiro Agrícola - Departamento de Engenharia/DEG - Universidade Federal de Lavras/UFLA - emmochizuki@hotmail.com

4. Professor Adjunto IV , M.Sc. - Departamento de Engenharia/DEG - Universidade Federal de Lavras/UFLA - claubote@ufla.br
} 
dados estimados pela "Food and Agriculture Organization" (FAO) era de 908,104 milhões cabeças, com uma produção anual de 90,909 milhões de toneladas de carne (FAOSTAT, 2001). No Brasil o plantel em 2000 constituía-se de 27,320 milhões de cabeças, com uma produção anual de 1.804 milhões de toneladas de carne. Considerando uma produção média de 8,60 litros de dejetos líquidos por animal por dia (OLIVEIRA, 1993), tem-se a geração de aproximadamente $235.000 \mathrm{~m}^{3}$ diários de efluentes, que correspondem a um potencial poluidor de 131 milhões de habitantes para uma $\mathrm{DBO}_{5}$ média de $30.000 \mathrm{mg} . \mathrm{L}^{-1}$.

Até a década de 70 , a densidade de animais na suinocultura proporcionava uma geração de dejetos capaz de ser absorvida pelo solo, não se constituindo ainda em grave problema. Com a evolução da suinocultura, os animais passaram a ser confinados em densidades cada vez maiores, aumentando a quantidade de dejetos produzidos e passando a ser um importante agente impactante. Além disso, o confinamento ocasionou um aumento crescente no uso de água de higienização (lavação), aumentando o volume de dejetos e sua diluição (OLIVEIRA, 1997).

A quantidade de dejetos produzida pelos suínos é função do desenvolvimento dos animais, variando de 4,9 a 8,5\% de seu peso vivo/dia, para faixa de 15 a 100 $\mathrm{kg}$. O volume total de água residuária é função da quantidade de água excretada pelos animais, desperdiçada nos bebedouros e do volume de água utilizado na lavação das instalações (OLIVEIRA, 1993). A concentração de sólidos nos dejetos líquidos em sistemas de confinamento intensivo apresenta valores entre 0,1 a $3 \%$ (OLIVEIRA, 1997).

A utilização de sistemas anaeróbios para o tratamento de águas residuárias possibilita a produção de energia do biogás, demanda pequena área, são de simples construção e permitem a utilização de nutrientes (nitrogênio e fósforo) após o tratamento em outras atividades agrícolas.

Os reatores anaeróbios convencionais utilizados no tratamento de água residuária da suinocultura apresentam o inconveniente de possuírem elevados tempos de detenção hidráulica (TDH), em torno de alguns dias. Esse TDH elevado é utilizado de forma a permitir o crescimento dos microrganismos decompositores envolvidos no processo. Com o aumento do conhecimento científico do processo anaeróbio, foi possível desvincular o TDH do tempo de retenção celular TRC (tempo de retenção celular), utilizando-se TDH de apenas algumas horas e TRC de vários dias (METCALF \& EDDY, 2003).
Entre os reatores anaeróbios de última geração, destaca-se o reator anaeróbio de manta de lodo (UASB). Esse reator é considerado por muitos um avanço na utilização da tecnologia anaeróbia no tratamento de águas residuárias de natureza simples ou complexa, de alta ou baixa concentração, solúveis ou com materiais particulados (KATO et al., 1999).

O reator UASB dispensa o uso de materiais de enchimento por desenvolver e reter biomassa concentrada e de alta atividade metanogênica, principalmente em sua parte inferior, na forma de grânulos e/ou flocos densos, denominada zona de reação ativa. Isso é conseguido por meio de uma seleção interna imposta pela velocidade do fluxo ascendente, tipo de substrato e ainda da carga orgânica volumétrica (COV). Esses fatores levados em consideração desde a partida do sistema permitem o cultivo do lodo. A incorporação de um dispositivo interno de separação sólido/gás/líquido faz também com que o reator trabalhe com elevados TRC, mesmo com TDH baixos.

\section{MATERIAL E MÉTODOS}

O experimento foi desenvolvido no Laboratório de Análise de Águas do Departamento de Engenharia (LAADEG) da Universidade Federal de Lavras (UFLA). A pesquisa foi desenvolvida em um sistema composto de três unidades experimentais: tanque de acidificação e equalização (TAE), reator anaeróbio de manta de lodo (UASB) e lagoa aerada facultativa (LAF). Neste trabalho, foram avaliados somente os parâmetros relacionados com o reator UASB no tratamento de águas residuárias de suinocultura.

Durante um período de 582 dias, os dejetos utilizados foram coletados das instalações do Setor de Suinocultura do Departamento de Zootecnia da UFLA. As instalações eram lavadas diariamente pela manhã, antes de ser ministrada a ração. As lavações realizadas com mangueira continham estrume fresco, urina e resto de alimentos, os quais eram canalizados até se unirem em rede efluente única. A partir desse ponto, foi feita a coleta das águas residuárias para tratamento no UASB mantido no interior do laboratório. O número de animais em criação girava em torno de 500, variando de acordo com os abates e nascimentos.

A alimentação do sistema foi realizada por "bateladas" no TAE e, posteriormente, o efluente foi bombeado para o sistema de aquecimento, para manter constante a temperatura afluente ao reator (mesofilico), encaminhado ao reator UASB e, após o tratamento anaeróbio, conduzido para a LAF. Os volumes do TAE, 
UASB e LAF foram de 38; 11,7 e 16 litros, respectivamente. $\mathrm{O}$ volume útil do TAE foi três vezes superior ao volume do reator UASB devido à necessidade de se acidificar e hidrolisar os compostos presentes na forma de sólidos totais. O fluxograma do sistema, a representação esquemática e o sistema implantado podem ser visualizados nas Figuras 01 e 02, respectivamente.

Na recarga (alimentação em batelada) do sistema, tomou-se o cuidado de se coletar o efluente da forma mais homogênea possível, para que houvesse uma representatividade real desse material. As recargas no TAE foram realizadas todas as vezes que se bombeava praticamente todo o volume útil desse. A alimentação do sistema foi realizada por bomba de membrana, marca MUELLER, modelo (FCO 0107 PCS V), com uma capacidade de vazão de 0,1 a $12 \mathrm{~L} \cdot \mathrm{h}^{-1}$.

O reator UASB foi construído de vidro $3 \mathrm{~mm}$ possuindo um volume útil de 11,7 litros. O separador trifásico foi confeccionado com formato piramidal, também constituído de vidro. O nível do biogás dentro do reator UASB foi mantido graças à atuação de um equalizador de pressão.

O monitoramento do sistema foi realizado com a determinação de parâmetros físico-químicos do afluente e do efluente do TAE, efluente do reator UASB e efluente da LAF, denominados respectivamente: A-TAE, E-TAE, E-UASB e E-LAF. Os seguintes parâmetros físico-químicos foram analisados: vazão, temperatura, $\mathrm{pH}$, demanda química de oxigênio total $\left(\mathrm{DQO}_{\mathrm{T}}\right)$, sólidos totais (ST) e sólidos voláteis totais (SVT). As amostras foram analisadas de acordo com APHA (1995). As determinações de $\mathrm{pH}$, temperatura e vazão foram realizadas diariamente, enquanto as análises de $\mathrm{DQO}_{\mathrm{T}}$, ST, SFT e SVT, amostras simples, foram realizadas sempre que se fazia a recarga no TAE.

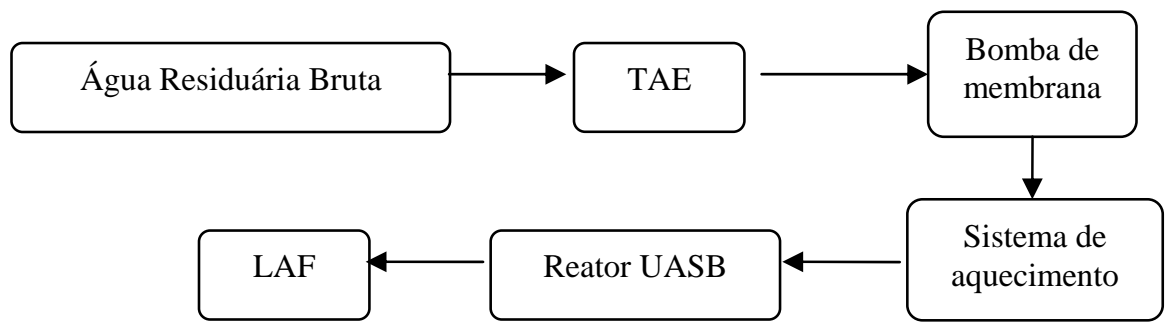

FIGURA 1 - Fluxograma do sistema proposto.

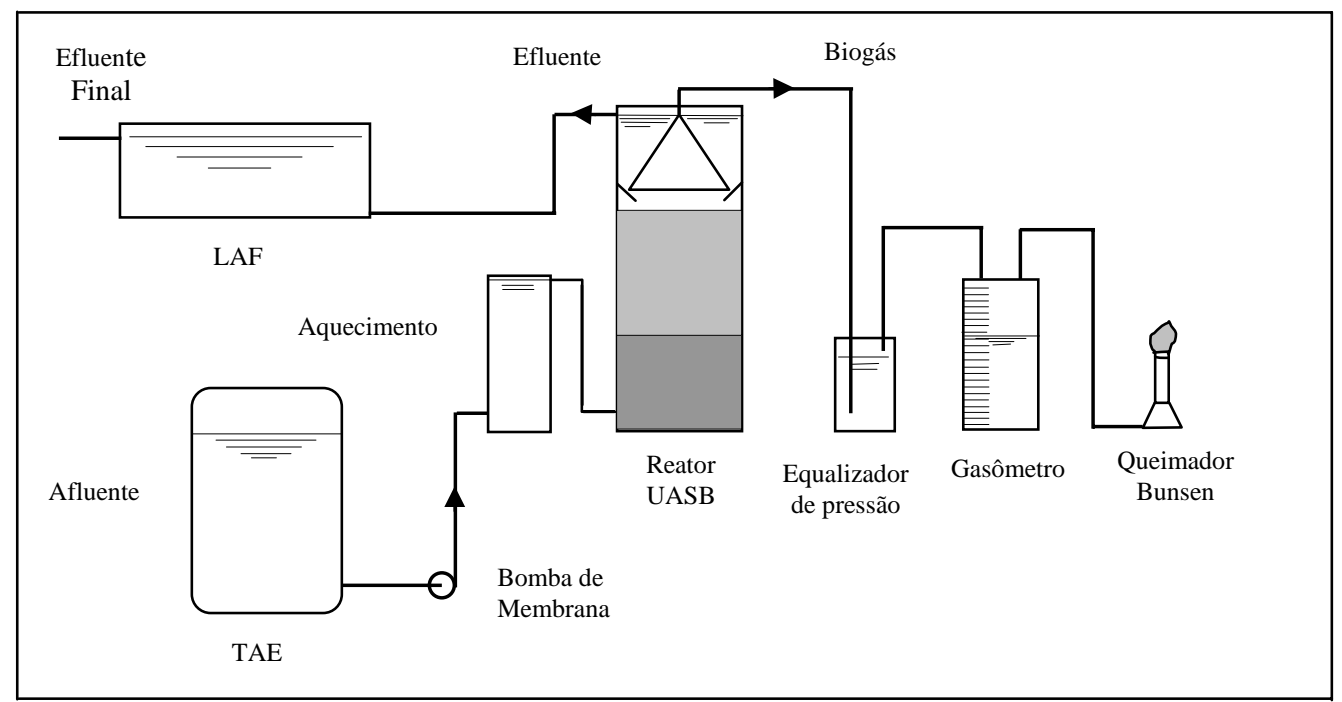

FIGURA 2 - Representação esquemática do sistema proposto. 
Os parâmetros mantidos constantes após a fase de "steady-state" no reator UASB foram o tempo de detenção hidráulica (TDH) e a temperatura. O TDH adotado foi de 30 horas, ao passo que a temperatura adotada foi de $30^{\circ} \mathrm{C}$. O sistema de aquecimento e o reator UASB foram revestidos com "isopor", de maneira a manter constante a temperatura mesofílica e minimizarem a troca de calor com o meio.

O trabalho estatístico foi realizado com softwares Microsoft ${ }^{\circledR}$ Excel XP ${ }^{\circledR}$ e Statistica ${ }^{\circledR} 5.0$ utilizando os procedimentos descritos por Levine et al. (2000).
Apesar de na pesquisa ter-se versado sobre um sistema de tratamento das águas residuárias da suinocultura composto pelo TAE, UASB e LAF, neste trabalho são analisados somente os parâmetros relacionados com o desempenho do reator anaeróbio de manta de lodo (UASB).

\section{RESULTADOS E DISCUSSÃO}

Os valores médios, mínimos, máximos, medianas, coeficientes de variação e desvios-padrão do afluente e do efluente do reator UASB estão apresentados na Tabela 1.

TABELA 1 - Características físicas e químicas do afluente e do efluente do reator UASB.

\begin{tabular}{|c|c|c|c|c|c|c|c|}
\hline \multicolumn{2}{|c|}{ Parâmetro } & \multirow{2}{*}{$\begin{array}{r}\text { Média } \\
1806\end{array}$} & \multirow{2}{*}{$\begin{array}{c}\text { Mínimo } \\
293\end{array}$} & \multirow{2}{*}{$\begin{array}{c}\text { Máximo } \\
5795\end{array}$} & \multirow{2}{*}{$\begin{array}{c}\text { Mediana } \\
1606\end{array}$} & \multirow{2}{*}{$\begin{array}{c}\begin{array}{c}\text { Desvio Pa- } \\
\text { drão }\end{array} \\
1073\end{array}$} & \multirow{2}{*}{$\begin{array}{c}\begin{array}{c}\text { Coef. de } \\
\text { Variação }\end{array} \\
0,59\end{array}$} \\
\hline $\mathrm{DQO}_{\mathrm{T}}$ & Afluente & & & & & & \\
\hline$\left(m g . L^{-1}\right)$ & Efluente & 283 & 44 & 1157 & 264 & 180 & 0,64 \\
\hline ST & Afluente & 1810 & 484 & 4780 & 1594 & 897 & 0,50 \\
\hline$\left(\mathrm{mg} \cdot \mathrm{L}^{-1}\right)$ & Efluente & 758 & 292 & 1612 & 690 & 282 & 0,37 \\
\hline SFT & Afluente & 570 & 100 & 1760 & 513 & 297 & 0,52 \\
\hline$\left(\mathrm{mg} \cdot \mathrm{L}^{-1}\right)$ & Efluente & 426 & 84 & 950 & 380 & 193 & 0,45 \\
\hline \multirow{2}{*}{ SVT $\left(\mathrm{mg} \cdot \mathrm{L}^{-1}\right)$} & Afluente & 1240 & 256 & 4467 & 1063 & 753 & 0,61 \\
\hline & Efluente & 332 & 35 & 851 & 304 & 159 & 0,48 \\
\hline \multirow{2}{*}{ PH } & Afluente & 7,30 & 5,97 & 8,90 & 7,28 & 0,47 & 0,06 \\
\hline & Efluente & 7,37 & 6,16 & 8,85 & 7,37 & 0,41 & 0,06 \\
\hline \multirow{2}{*}{$\begin{array}{l}\text { Temperatura } \\
\qquad\left({ }^{\circ} \mathrm{C}\right)\end{array}$} & UASB & 27 & 21 & 37 & 27 & 3 & 0,11 \\
\hline & Ambiente & 23 & 17 & 29 & 23 & 2 & 0,10 \\
\hline \multicolumn{2}{|l|}{ Vazão $\left(L \cdot h^{-1}\right)$} & 0,385 & 0,200 & 0,900 & 0,380 & 0,090 & 0,23 \\
\hline \multicolumn{2}{|l|}{ TDH (horas) } & 30 & 13 & 59 & 42 & 7,31 & 0,23 \\
\hline \multicolumn{2}{|c|}{$\operatorname{CHV}\left(\mathrm{m}^{3} \cdot \mathrm{m}^{-3} \cdot \mathrm{d}^{-1}\right)$} & 0,80 & 0,41 & 1,85 & 0,77 & 0,18 & 0,23 \\
\hline \multicolumn{2}{|c|}{$\operatorname{COV}\left(\mathrm{kgDQO} \cdot \mathrm{m}^{-3} \cdot \mathrm{d}^{-1}\right)$} & 1,42 & 0,21 & 4,99 & 1,22 & 0,89 & 0,63 \\
\hline \multicolumn{2}{|c|}{ Eficiência $\mathrm{DQO}_{\mathrm{T}}(\%)$} & 84 & 56,7 & 97,5 & 84 & 9,8 & 0,12 \\
\hline \multicolumn{2}{|c|}{ Eficiência ST (\%) } & 58,1 & 6,9 & 84,0 & 55,8 & 19 & 0,32 \\
\hline \multicolumn{2}{|c|}{ Eficiência (SFT) (\%) } & 25,3 & $-{ }^{*}$ & 85,4 & 18,30 & 51 & 2,02 \\
\hline \multicolumn{2}{|c|}{ Eficiência (SVT) (\%) } & 73,2 & 15,5 & 98,7 & 70,9 & 16 & 0,22 \\
\hline
\end{tabular}


O período de partida durou 96 dias. Portanto, neste trabalho consideram-se os valores apresentados desse dia em diante, até o $582^{\circ}$ dia, ou seja, o tempo de monitoramento de 486 dias.

Apesar de ter sido estipulada uma vazão de acordo com o TDH desejado, houve variação na vazão, como pode ser verificado na Figura 3. Essa variação é inerente ao fato de o sistema ter trabalhado com carga excessiva de sólidos e não possuir unidade separadora dos mesmos. Os sólidos acumulavam-se nas tubulações anteriores à bomba, diminuindo a vazão e causando entupimento. A vazão média no sistema foi de $0,385 \mathrm{~L} . \mathrm{h}^{-1}$, com valor mínimo de $0,2 \mathrm{~L} \cdot \mathrm{h}^{-1}$ e máximo de $0,9 \mathrm{~L} \cdot \mathrm{h}^{-1}$. O TDH médio do UASB foi de 30 horas. Os valores mínimo e máximo foram de 13 e 59 horas, respectivamente. Apesar de a variação da vazão afetar a eficiência, de forma alguma prejudicou o experimento, já que sistemas em escala plena sofrem constantes variações inerentes ao processo industrial.

A carga hidráulica volumétrica (CHV) média foi de $0,8 \mathrm{~m}^{3} \cdot \mathrm{m}^{-3} \cdot \mathrm{d}^{-1}$, enquanto os valores mínimo e máximo foram de 0,41 e $1,85 \mathrm{~m}^{3} \cdot \mathrm{m}^{-3} \cdot \mathrm{d}^{-1}$, respectivamente. Campos (1998) relata que, para despejos solúveis, o valor da CHV não deve ultrapassar $5 \mathrm{~m}^{3} \cdot \mathrm{m}^{-3} \cdot \mathrm{d}^{-1}$, ficando as CHV no UASB bem abaixo do valor máximo recomendado. Valores acima de $5 \mathrm{~m}^{3} \cdot \mathrm{m}^{-3} \cdot \mathrm{d}^{-1}$ poderiam prejudicar o funcionamento do sistema, causando perda excessiva da biomassa, diminuição do grau de estabilização dos sólidos e possibilidade de falha do sistema, pois o tempo de permanência da biomassa pode se tornar inferior ao seu crescimento.

A temperatura no reator UASB, apesar de ter sido estimada em $30^{\circ} \mathrm{C}$, apresentou valor médio de $27^{\circ} \mathrm{C}$, variando, devido a fatores climáticos. A temperatura ambiente variou de 17 a $29^{\circ} \mathrm{C}$, com média de $23^{\circ} \mathrm{C}$.

$\mathrm{O} \mathrm{pH}$ afluente ao reator UASB apresentou valores compreendidos entre 5,9 e 8,9, com um valor médio de 7,3. O efluente apresentou valores entre 6,2 e 8,9, com um valor médio de 7,4. Analisando o valor médio de entrada e saída do sistema, vê-se que não houve diferença acentuada entre esses, demonstrando boas condições de tamponamento da unidade. Esse é um detalhe importante quando se considera o custo de operação do reator UASB, pois se houvesse variações grandes de pH, seria necessária a adição de substâncias químicas para tamponamento.

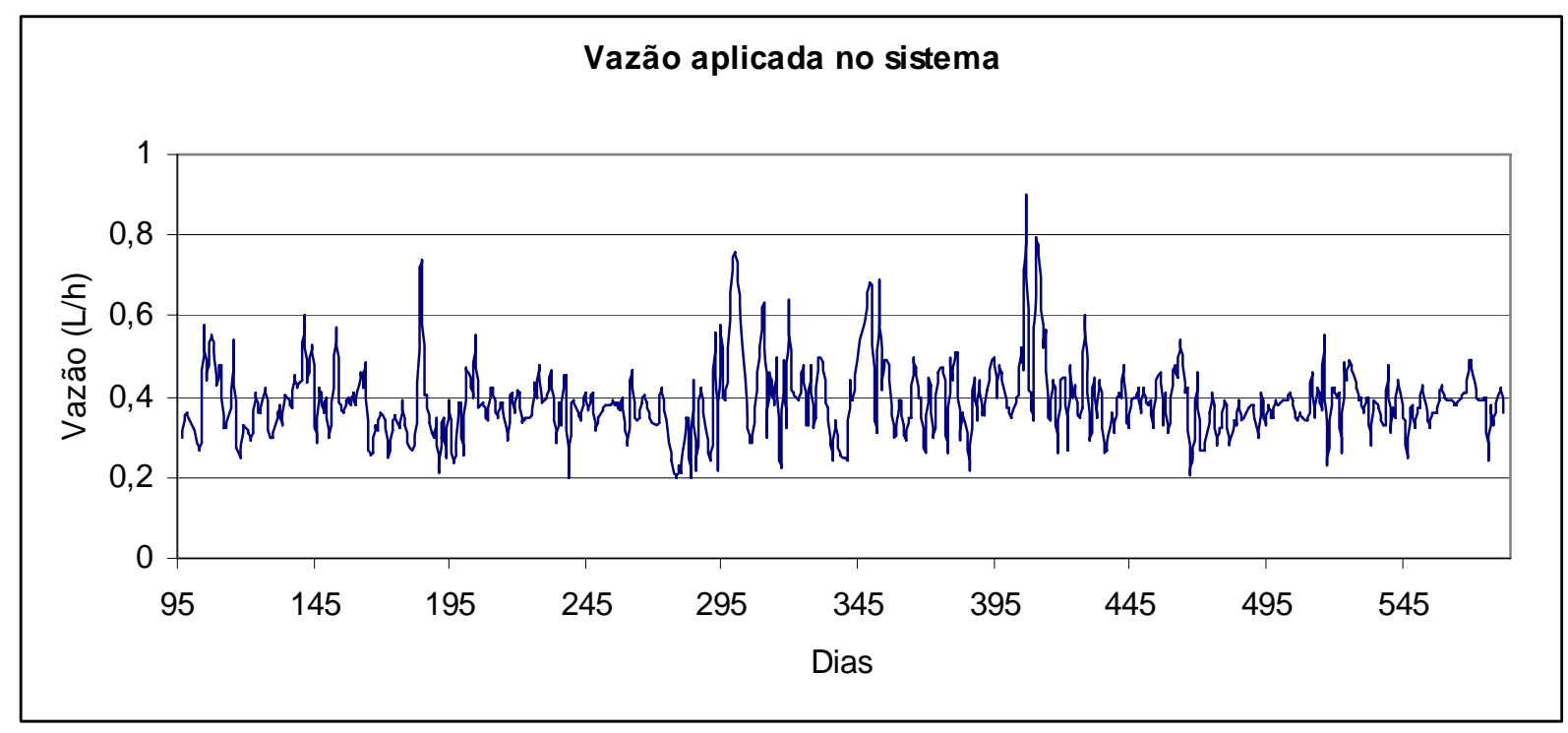

FIGURA 3 - Variação da vazão aplicada no sistema. 
A amplitude elevada dos valores de $\mathrm{pH}$ observados no afluente e efluente pode ser explicada pela utilização de produtos de limpeza (desinfetantes, detergentes, etc.) em diferentes concentrações no momento da lavação das instalações, que influenciam o pH. Apesar de terem sido verificados valores de coeficientes de variação idênticos $(0,06)$, isso não significa que qualquer variação no $\mathrm{pH}$ do afluente resultasse em variação do efluente. Em sua maior parte, as variações ocorreram em momentos distintos da pesquisa, e não em momentos instantâneos.

Analisando-se a Figura 4, verifica-se que os valores centrais do $\mathrm{pH}$ afluente e efluente situaram-se de 7,0 a 7,6 e 7,0 a 7,7, respectivamente. Os dados tanto do afluente quanto do efluente, apresentaram distribuição próxima à simétrica. Portanto, os valores mínimos e máximos observados não distorceram o valor da média, sendo esse o valor representativo do $\mathrm{pH}$. Nota-se também que a mediana apresentou valor próximo à média encontrada $(7,3)$.

Ocorreram grandes variações da $\mathrm{DQO}_{\mathrm{T}}$ afluente ao reator UASB durante o período de monitoramento, como pode ser visualizado na Figura 5. Essa variação se explica pelo acúmulo de sólidos no fundo do TAE, os quais ocasionalmente eram bombeados para dentro do reator UASB. A $\mathrm{DQO}_{\mathrm{T}}$ afluente apresentou um valor mínimo e máximo de 293 e 5795 mg. $\mathrm{L}^{-1}$, respectivamente, com valor médio de 1806 mg. $\mathrm{L}^{-1}$. Os valores da $\mathrm{DQO}_{\mathrm{T}}$ efluente do reator UASB ficaram em uma faixa compreendida entre $44 \mathrm{e}$
$1157 \mathrm{mg} . \mathrm{L}^{-1}$. O valor médio da $\mathrm{DQO}_{\mathrm{T}}$ efluente foi de $283 \mathrm{mg} . \mathrm{L}^{-1}$.

Pela análise dos gráficos das distribuições dos valores da $\mathrm{DQO}_{\mathrm{T}}$ afluente e efluente (Figura 6), pode-se observar que os quartis centrais da DQO afluente ficaram entre 1023 e $2194 \mathrm{mg} . \mathrm{L}^{-1}$ e os do efluente, entre 153 e 375 mg. $\mathrm{L}^{-1}$. Nota-se que os valores extremos, tanto no afluente quanto no efluente, influenciaram a determinação da média aritmética. Esses valores, apesar de extremos, foram reais, devido ao correlacionamento referente ao aumento dos sólidos totais. A mediana foi de 1606 e 264 mg.. - $^{-1}$ para o afluente e o efluente, respectivamente. Observa-se que os valores da mediana foram bastante diferentes dos encontrados na média. O coeficiente de variação no efluente foi maior, indicando uma maior susceptibilidade às variações da carga orgânica afluente.

A eficiência de remoção da $\mathrm{DQO}_{\mathrm{T}}$ média foi de $84 \%$, variando de 56,7 a $97,5 \%$. Os valores mais baixos de eficiência geralmente foram relacionados com valores elevados de sólidos totais afluentes que estavam acumulados no TAE e que, posteriormente, foram bombeados para o UASB. A variação na eficiência de remoção de $\mathrm{DQO}_{\mathrm{T}}$ pode ser visualizada na Figura 7.

Considerando a mediana para o cálculo da eficiência de remoção, eliminando assim a influência dos valores extremos, obtém-se o valor de $83 \%$, próximo à eficiência média citada anteriormente. Analisando a Figura 8, nota-se que os valores centrais da eficiência ficaram compreendidos entre 72 e $89 \%$, indicando boa eficiência de remoção de matéria orgânica.

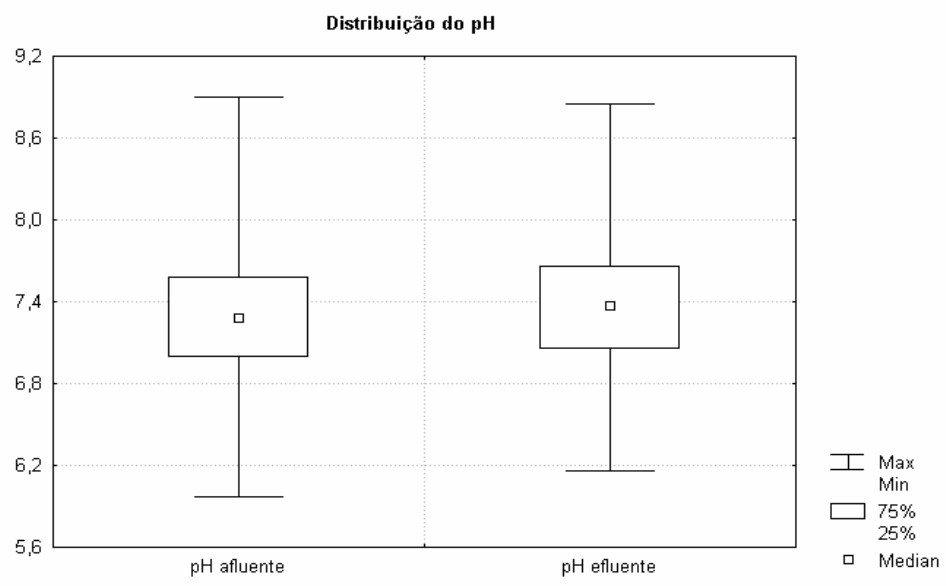

FIGURA 4 - Distribuição dos valores do pH afluente e efluente. 


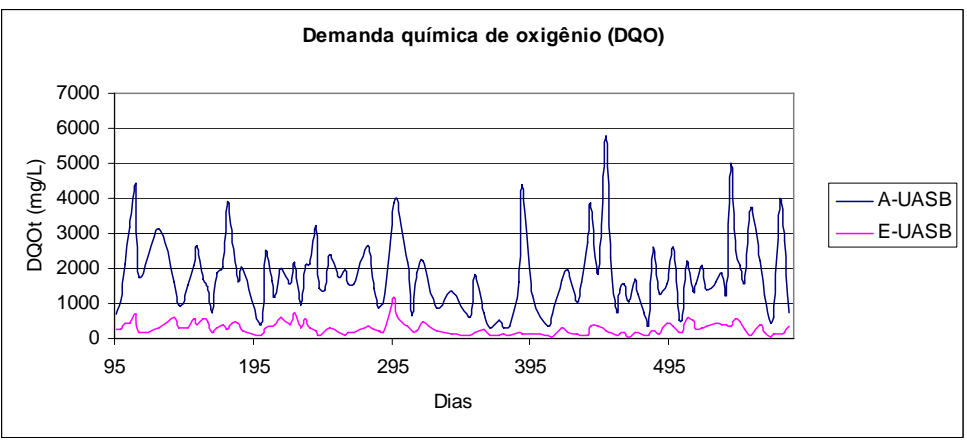

FIGURA 5 - Variação da DQO afluente e efluente.

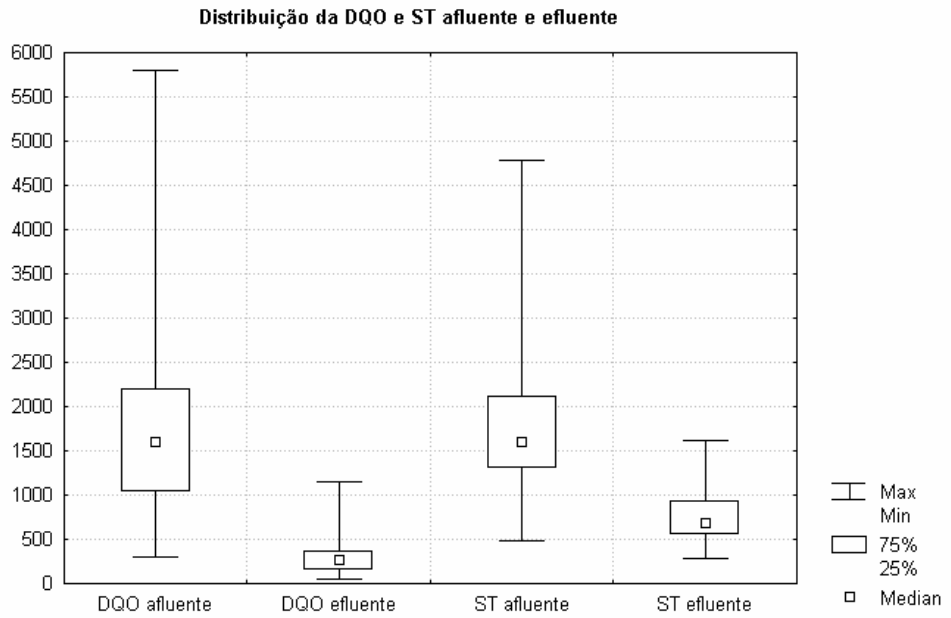

FIGURA 6 - Distribuição da $\mathrm{DQO}_{\mathrm{T}}$ afluente e efluente e ST afluente e efluente.

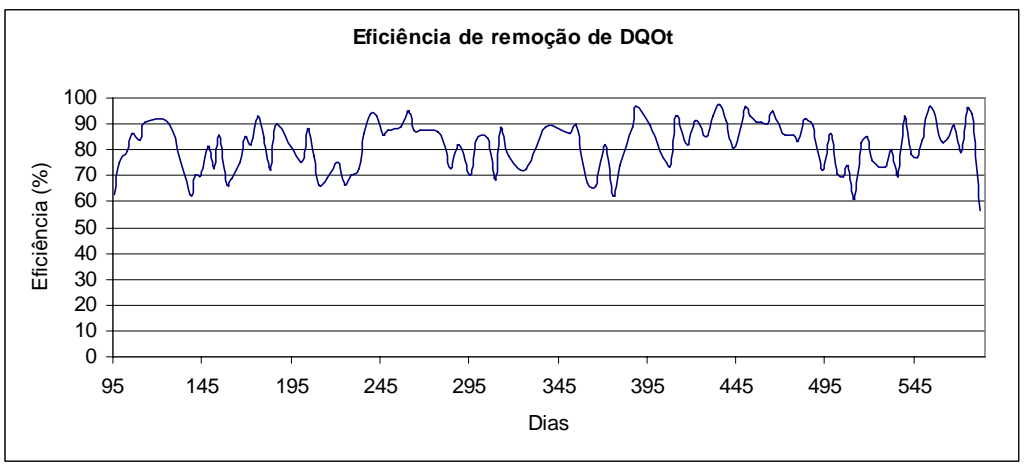

FIGURA 7 - Variação da eficiência de remoção de DQO ${ }_{\mathrm{T}}$.

Ciênc. agrotec., Lavras, v. 29, n. 2, p. 390-399, mar./abr., 2005 


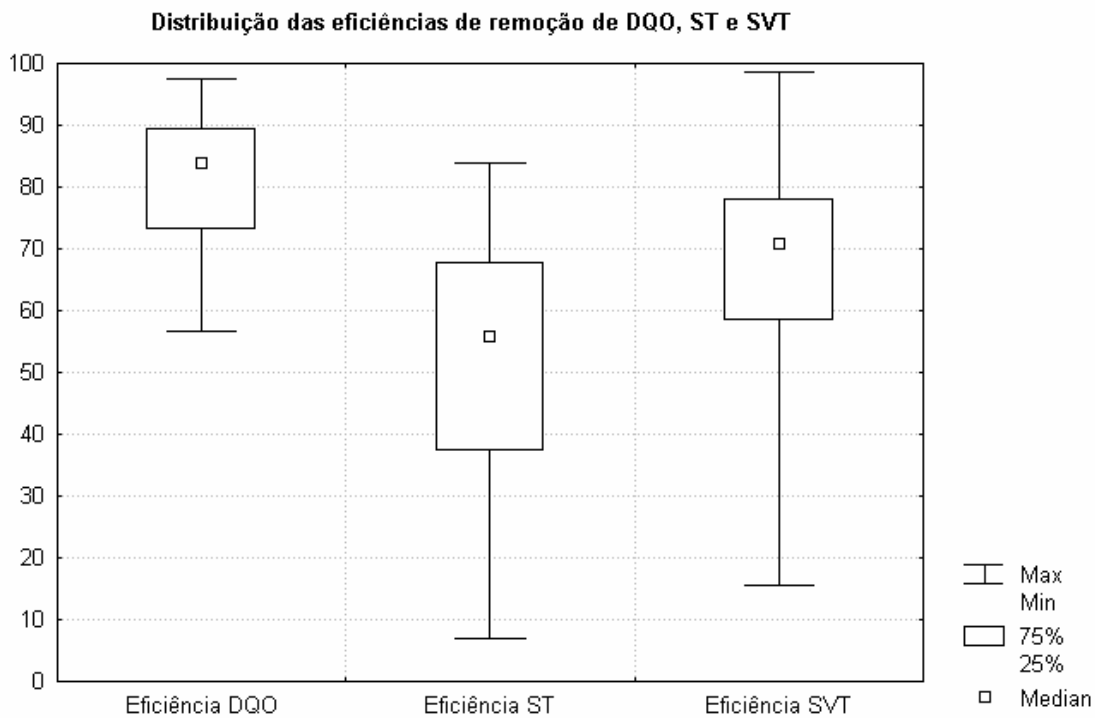

FIGURA 8 - Distribuição da eficiência de remoção de DQO ${ }_{\mathrm{T}}$, ST e SVT.

A carga orgânica volumétrica (COV) apresentou valor médio de 1,42 $\mathrm{kgDQO}_{\mathrm{T}} \cdot \mathrm{m}^{-3} \cdot \mathrm{d}^{-1}$, com valores compreendidos entre 0,21 e $4,99 \mathrm{kgDQO}_{\mathrm{T}} \cdot \mathrm{m}^{-3} \cdot \mathrm{d}^{-1}$. Essa variação é explicada pelos mesmos motivos da variação da $\mathrm{DQO}_{\mathrm{T}}$ afluente e da vazão, descritos anteriormente.

O valor da eficiência média de remoção encontrado de $85 \%$ foi semelhante ao citado por Oliveira (1997), tratando dejetos de suínos. O referido autor analisou o comportamento de dois reatores UASB sob diferentes condições de cargas orgânicas e tempos de detenção hidráulica. Para o tempo de detenção de 30 horas, a eficiência média de remoção de $\mathrm{DQO}_{\mathrm{T}}$ foi de $90 \%$ para uma COV de $0,82 \mathrm{kgDQO}_{\mathrm{T}} \cdot \mathrm{m}^{-3} \cdot \mathrm{d}^{-1}$ e de $88 \%$ para uma COV de 1,62 $\mathrm{kgDQO}_{\mathrm{T}} \cdot \mathrm{m}^{-3} \cdot \mathrm{d}^{-1}$.

Zhang \& Dague (1995) avaliaram o desempenho do reator anaeróbio seqüencial, em batelada, no tratamento de águas residuárias de suinocultura com um tempo de detenção de 72 horas e COV de $1,47 \mathrm{kgDQO}_{\mathrm{T}} \cdot \mathrm{m}^{-3} \cdot \mathrm{d}^{-1}$, obtendo uma remoção de $\mathrm{DQO}_{T}$ de $59 \%$. Ng \& Chin (1988) alcançaram uma eficiência de remoção de $\mathrm{DQO}_{\mathrm{T}}$ de $78 \%$ para uma COV de $1,47 \mathrm{kgDQO}_{\mathrm{T}} \cdot \mathrm{m}^{-3} \cdot \mathrm{d}^{-1} 1 \mathrm{em}$ um filtro anaeróbio de leito expandido. Os valores apresentados de remoção de $\mathrm{DQO}_{\mathrm{T}}$ no presente trabalho de pesquisa foram superiores aos encontrados por outros autores utilizando sistemas de tratamento diferentes, demonstrando a potencialidade de uso do reator UASB no tratamento de águas residuárias suinícolas.

Os sólidos totais (ST) apresentaram valores compreendidos entre 484 e $4780 \mathrm{mg} . \mathrm{L}^{-1}$ no afluente e 292 e
1612 mg.L $\mathrm{L}^{-1}$ no efluente. Os valores médios, afluente e efluente, foram de 1810 e $758 \mathrm{mg} . \mathrm{L}^{-1}$, respectivamente. Os sólidos fixos totais (SFT) apresentaram valores médios de 570 e 426 mg. $\mathrm{L}^{-1}$ no afluente e efluente, respectivamente. A faixa de variação do afluente ficou entre 100 e $1760 \mathrm{mg} . \mathrm{L}^{-1}$, ao passo que a variação do efluente apresentou valores compreendidos entre 84 e $950 \mathrm{mg} . \mathrm{L}^{-}$ ${ }^{1}$. Os valores de sólidos voláteis totais (SVT) afluentes apresentaram valores entre 256 e 4467 mg. $\mathrm{L}^{-1}$, com um valor médio de $1240 \mathrm{mg} . \mathrm{L}^{-1}$. O efluente apresentou valores compreendidos entre 35 e 851 mg. $\mathrm{L}^{-1}$, com um valor médio de $332 \mathrm{mg} . \mathrm{L}^{-1}$.

A exemplo da $\mathrm{DQO}_{\mathrm{T}}$, os valores médios de ST afluentes e efluentes foram afetados pelos valores extremos, como pode ser observado na Figura 6. Os valores centrais dos ST afluentes foram de 1293 a 2122 mg.L $\mathrm{L}^{-1}$, com uma mediana no valor de $1594 \mathrm{mg} . \mathrm{L}^{-1}$. Os valores centrais do efluente ficaram compreendidos entre 545 e 947 mg. $\mathrm{L}^{-1}$, com mediana de 690 mg.. ${ }^{-1}$. Como se pode observar, os valores da média aritmética foram afetados pelos valores extremos encontrados durante o monitoramento.

A variação da quantidade de sólidos totais no afluente do reator UASB pode ser explicada pelo acúmulo de sólidos no fundo do TAE, e que, posteriormente, foram bombeados para dentro daquela unidade. Nota-se na Figura 9 que o sistema possui uma tendência em minimizar a variação de sólidos totais afluente. 


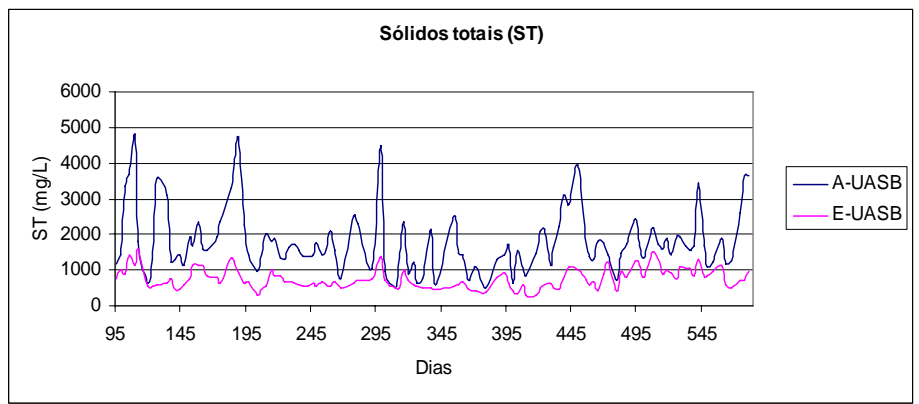

FIGURA 9 - Variação da eficiência de remoção de ST.

A eficiência média de remoção de sólidos totais foi de $58,1 \%$, variando entre 6,9 e $84 \%$. A eficiência média de remoção de sólidos fixos totais foi de $25,3 \%$. Utilizando-se a mediana, obtém-se uma eficiência de remoção de sólidos totais de 55,8\%. Em alguns momentos do monitoramento, a eficiência de remoção de SFT apresentou valores negativos, indicando a eliminação de sólidos inorgânicos acumulados no reator UASB. A eficiência de remoção de SVT sempre foi positiva, indicando remoções da parte orgânica dos sólidos totais. O valor médio foi de 73,2\%, o mínimo de $15,5 \%$ e o máximo de $98,7 \%$.

Os valores centrais de remoção de ST e SVT foram de $37,3 \%$ a $68,1 \%$ e $57,4 \%$ a $78,9 \%$, respectivamente. O reator UASB apresentou boa remoção da parte orgânica dos sólidos contidos nas águas residuárias de suinocultura, representada pelos SVT, de acordo com APHA (1995). A mediana foi de $55,8 \%$ para ST e 70,9\% para SVT, bem próxima à média aritmética, indicando uma distribuição mais simétrica do que a apresentada pela concentração de ST (Figura 9). Esse resultado significa que, apesar da variação na concentração dos sólidos afluentes, esses não influenciaram diretamente a eficiência, demonstrando boa capacidade de absorção das variações de carga.

Pela análise dos parâmetros observados, nota-se que o sistema apresentou resultados satisfatórios na remoção da carga orgânica em termos de DQOT. Mesmo com a variação inerente à bomba de membrana utilizada, foi obtido bom desempenho do reator UASB, podendo ser comparável com os resultados obtidos por Oliveira (1997).

\section{CONCLUSÕES}

Para o tempo de detenção hidráulica de 30 horas e temperatura de $30^{\circ} \mathrm{C}$ adotados, o reator UASB apresentou boa remoção de $\mathrm{DQO}_{\mathrm{T}}$, em torno de $84 \%$.
A remoção de ST foi satisfatória, principalmente levando em consideração que o sistema trabalhou com uma carga excessiva de sólidos, já que não houve tratamento preliminar com retenção e separação de sólidos, nem na saída do efluente líquido da granja, nem no sistema de bancada laboratorial.

Comparando os resultados aqui obtidos com outros descritos na literatura pertinente, como por exemplo: reator anaeróbio seqüencial em batelada e filtro anaeróbio de leito expandido, avaliados por Ng \& Chin (1998) e Zhang \& Dague (1995), os quais apresentaram eficiências de 59\% e $78 \%$, respectivamente, o reator UASB pesquisado demonstrou desempenho superior a esses.

O funcionamento do reator mostrou-se estável, com boas condições de tamponamento, retenção e digestibilidade de sólidos, demonstrando claramente que os parâmetros adotados permitiram a boa eficiência do sistema.

\section{AGRADECIMENTOS}

Ao Departamento de Engenharia da UFLA, por ceder o laboratório de Análise de Água do Departamento de Engenharia (LAADEG), onde a pesquisa foi desenvolvida. Ao Núcleo de Inovação Tecnológica NIT, resultante do convênio celebrado entre a UFLA e a Empresa de Base Tecnológica Global Ciência e Tecnologia - GCT. E também ao Conselho Nacional de Desenvolvimento Científico e Tecnológico - CNPq, pelo apoio e concessão de bolsas PIBIC.

\section{REFERÊNCIAS BIBLIOGRÁFICAS}

American Public Health Association. AMERICAN WATER WORKS ASSOCIATION. WATER POLLUTION CONTROL FEDERATION. Standard methods for the examination of water and wastewater. 15. ed. Washington, 1995. $1134 \mathrm{p}$. 
CAMPOS, C. M. M. Reatores anaeróbios de última geração. Lavras: UFLA, 1998. 59 p. Apostila.

CAMPOS, C. M. M.; HARDOIM, P. C.; BOTELHO, C. G.; SEVERO, J. C. A. Programa computacional para simulação e dimensionamento de sistemas de tratamento de dejetos suínos. In: CONGRESSO BRASILEIRO DE ENGENHARIA AGRÍCOLA, 28., 1999, Pelotas, RS. Anais... Pelotas: SBEA, 1999. CD-ROM.

FAOSTAT. FAO Statistical Databases. 2001. Disponível em: <http://apps.fao.org>. Acesso em: 10 set. 2001.

KATO, M. T. et al. Configurações de reatores anaeróbios. In: CAMPOS, J. R. Tratamento de esgotos sanitários por processo anaeróbio e disposição controlada no solo. Rio de Janeiro: ABES/PROSAB, 1999. cap. 3, p. 53-100, 405 p.

LEVINE, D. M.; BERENSON, M. L.; STEPHAN, D. Estatística: teoria e aplicações usando Microsoft ${ }^{\circledR}$ Excel em português. Rio de Janeiro: LTC, 2000. 811 p.
METCALF; EDDY. Wastewater engineering: treatment, disposal, reuse. 4. ed. [S.l.], 2003. 1819 p.

NG, W. I.; CHIN, K. K. Treatment of piggery wastewater by expanded-bed anaerobic filters. Biological Wastes, Barking, v. 26, n. 3, p. 215-228, 1988.

OLIVEIRA, P. A. V. de (Coord.). Manual de manejo e utilização dos dejetos de suínos. Concórdia: EMBRAPA-CNPSA, 1993. 188 p. (Documentos, 27).

OLIVEIRA, R. A. de. Efeito da concentração de sólidos suspensos do afluente no desempenho e características do lodo de reatores anaeróbios de fluxo ascendente com manta de lodo tratando águas residuárias de suinocultura. 1997. 359 f. Tese (Doutorado em Engenharia Civil) - Escola de Engenharia de São Carlos, Universidade de São Paulo, São Carlos, 1997.

ZHANG, R. H.; DAGUE, R. R. Treatment of swine wastes by the anaerobic sequencing batch reactors system. In: International Symposium on Agricultural and Food Processing Wastes, 7., 1995, Chicago. Proceedings... Chicago: ASAE, 1995. p. 301-308. 